\title{
Key drivers of patient satisfaction in lumbar spine surgery
}

\author{
Jay M. Levin, BA, ${ }^{1-3}$ Robert D. Winkelman, BA, ${ }^{1-3}$ Joseph E. Tanenbaum, BA, ${ }^{1,2,4,5}$ \\ Edward C. Benzel, MD, 1,3 Thomas E. Mroz, MD, ${ }^{1,3,5}$ and Michael P. Steinmetz, MD1,3
}

\begin{abstract}
${ }^{1}$ Center for Spine Health and Departments of ${ }^{3}$ Neurosurgery and ${ }^{4}$ Orthopaedic Surgery, Cleveland Clinic; ${ }^{2}$ Case Western Reserve University School of Medicine; and ${ }^{5}$ Department of Epidemiology and Biostatistics, Case Western Reserve University, Cleveland, Ohio
\end{abstract}

\begin{abstract}
OBJECTIVE The Patient Experience of Care, composed of 9 dimensions derived from the Hospital Consumer Assessment of Healthcare Providers and Systems (HCAHPS) survey, is being used by the Centers for Medicare \& Medicaid Services to adjust hospital reimbursement. Currently, there are minimal data on how scores on the constituent HCAHPS items impact the global dimension of satisfaction, the Overall Hospital Rating (OHR). The purpose of this study was to determine the key drivers of overall patient satisfaction in the setting of inpatient lumbar spine surgery.
\end{abstract}

METHODS Demographic and preoperative patient characteristics were obtained. Patients selecting a top-box score for OHR ( 9 or 10 of 10) were considered to be satisfied with their hospital experience. A baseline multivariable logistic regression model was then developed to analyze the association between patient characteristics and top-box OHR. Then, multivariable logistic regression models adjusting for patient-level covariates were used to determine the association between individual components of the HCAHPS survey and a top-box OHR.

RESULTS A total of 453 patients undergoing lumbar spine surgery were included, $80.1 \%$ of whom selected a top-box OHR. Diminishing overall health status $(\mathrm{OR} 0.63,95 \% \mathrm{Cl} 0.43-0.91)$ was negatively associated with top-box OHR. After adjusting for potential confounders, the survey items that were associated with the greatest increased odds of selecting a top-box OHR were: staff always did everything they could to help with pain (OR 12.5, 95\% $\mathrm{Cl} 6.6-23.7)$, and nurses were always respectful (OR 11.0, 95\% $\mathrm{Cl} 5.3-22.6$ ).

CONCLUSIONS Patient experience of care is increasingly being used to determine hospital and physician reimbursement. The present study analyzed the key drivers of patient experience among patients undergoing lumbar spine surgery and found several important associations. Patient overall health status was associated with top-box OHR. After adjusting for potential confounders, staff always doing everything they could to help with pain and nurses always being respectful were the strongest predictors of overall satisfaction in this population. These findings highlight opportunities for quality improvement efforts in the spine care setting.

https://thejns.org/doi/abs/10.3171/2017.10.SPINE17732

KEYWORDS patient satisfaction; lumbar spine surgery; HCAHPS; reimbursement; patient experience; back pain

$\mathrm{I}$ N 2011, the Centers for Medicare \& Medicaid Services (CMS) established Hospital Value-Based Purchasing (HVBP), a new hospital reimbursement system designed to shift payment models away from the traditional fee-for-service system and toward rewarding health care quality. Under HVBP, CMS withholds $2 \%$ of reimbursement from all hospitals, which are then redistributed from low-performing to high-performing hospitals based on their total performance score (TPS). ${ }^{27}$ Patient experience accounts for $25 \%$ of a hospital's TPS and is composed of 9 dimensions derived from the Hospital Consumer Assessment of Healthcare Providers and Systems (HCAHPS) survey. The percentage of patients who provide the highest possible HCAHPS response, termed a "top-box" response, for each dimension is used to calculate an institution's TPS. ${ }^{24}$ As the patient experience of care begins to play a more substantial role in evaluating the quality of care, it is important to identify which elements of hospital experience are most strongly associated with a highly satisfying overall patient experience. The need to identify the

ABBREVIATIONS CMS $=$ Centers for Medicare \& Medicaid Services; HCAHPS $=$ Hospital Consumer Assessment of Healthcare Providers and Systems; HVBP $=$ Hospital Value-Based Purchasing; ICD-9 = International Classification of Diseases, Ninth Revision; OHR = Overall Hospital Rating; PDQ = Pain Disability Questionnaire; PHQ-9 = Patient Health Questionnaire 9; TPS = total performance score.

SUBMITTED July 2, 2017. ACCEPTED October 17, 2017.

INCLUDE WHEN CITING Published online March 23, 2018; DOI: 10.3171/2017.10.SPINE17732. 
determinants of patient satisfaction is particularly acute for common and costly procedures, which have the largest potential impact on hospital reimbursement.

The incidence and cost of lumbar spine surgery are increasing in the United States. ${ }^{4,8,22,25,28}$ For example, aggregate hospital charges for surgical treatment of lumbar stenosis has increased by $40 \%$ between 2002 and 2007, mostly attributed to the rising rate of complex fusions performed. Additionally, as the United States population continues to age, the prevalence of spinal stenosis, the most common indication for lumbar spine surgery in patients older than 65 years, is expected to rise $59 \%$ to 64 million elderly adults by the year $2025 .{ }^{8}$ In this context, there exists a need to determine how to most effectively deliver a satisfying patient experience of care for patients undergoing lumbar surgery.

The nationwide trends in lumbar spine surgery and current lack of knowledge in the literature regarding determinants of patient satisfaction with the lumbar spine surgery experience highlight a significant gap in the literature. Our study therefore aims to identify the individual components of patient experience that are most strongly associated with a highly satisfying overall hospital experience during lumbar spine surgery. In our study, a top-box response to the Overall Hospital Rating (OHR) component of the HCAHPS survey-the only dimension of the survey that assesses the overall experience and is used in HVBP calculations - was used to measure the patients' overall experience in the hospital. These results will also highlight areas of patient care that hospitals and spine surgery departments might want to allocate resources toward in their quality improvement efforts.

\section{Methods}

\section{Overview and Study Design}

This is a retrospective study of HCAHPS surveys collected from patients who underwent lumbar spine surgery at a single tertiary hospital within an academic medical center between 2013 and 2015. Institutional review board approval was obtained prior to commencement of the study.

\section{Study Population}

HCAHPS surveys were queried from our patient experience database using International Classification of Diseases, Ninth Revision (ICD-9) diagnosis codes for degenerative lumbar spinal pathologies (Table 1). Initially, 495 HCAHPS surveys corresponding to patients who were hospitalized for a lumbar spine diagnosis were obtained. A total of 453 patients were found to have undergone either lumbar decompression or fusion during the inpatient stay that corresponded to their HCAHPS survey and were therefore included in our analysis.

A combination of retrospective chart review and our institution's Inpatient and Surgery Data Marts were used to obtain demographic and other patient characteristics, including age, sex, race, body mass index, median household income, history of lumbar spine surgery, and history of medical comorbidities. Since patient-specific income levels were unavailable, median household income was
TABLE 1. Coding system used to isolate potential spine surgery patients

\begin{tabular}{lc}
\hline \multicolumn{1}{c}{ Diagnosis } & ICD-9 Code \\
\hline Spondylolisthesis & 738.40 or 756.12 \\
\hline Lumbar spondylolysis & 756.11 \\
\hline Lumbar spondylosis & 721.3 or 721.42 \\
\hline Lumbar degenerative disc disease & 722.52 \\
\hline Lumbar spinal stenosis & 724.02 or 724.03 \\
\hline Lumbar disc displacement & 722.10 \\
\hline
\end{tabular}

estimated using the patient's ZIP code. Additionally, prospectively collected quality-of-life data were queried from our institution's Knowledge Program database to evaluate the preoperative health status of our population. These health measures included the EQ-5D, Patient Health Questionnaire 9 (PHQ-9), and Pain Disability Questionnaire (PDQ). The EQ-5D assesses 5 dimensions of the health state and assigns a utility value anywhere between 0.0 (death) and 1.0 (perfect health)., ${ }^{3,14}$ The PHQ-9 assesses for depression based on 9 Diagnostic and Statistical Manual of Mental Disorders IV criteria for major depressive disorder, with total scores ranging from 0 (not depressed) to 27 (severely depressed). ${ }^{18,19}$ The PDQ uses a $0-10$ scale to evaluate how pain influences the ability to function across 15 categories. Total PDQ scores range from 0 (optimal function) to 150 (total disability). ${ }^{10}$

\section{Outcome of Interest}

The HCAHPS survey is administered to a random sample of inpatients after discharge and is composed of the following 9 dimensions used to calculate the Patient Experience of Care domain for a hospital: Communication with Nurses, Communication with Doctors, Responsiveness of Hospital Staff, Pain Management, Communication about Medicines, Discharge Information, Care Transition, Hospital Cleanliness and Quietness, and Overall Hospital Rating. Our analysis on key drivers of satisfaction included 23 individual items from the HCAHPS survey.

HCAHPS results are reported as the percentage of patients who selected a top-box response, the most positive response to HCAHPS survey items. Our primary outcome was assessment of one of the global dimensions: Overall Hospital Rating. The OHR uses a scale of $0-10$, where 0 is the worst hospital possible and 10 is the best hospital possible. A score of 9 or 10 is considered a top-box hospital rating. Patients selecting a top-box response for OHR were considered to be satisfied with their hospital experience, while those selecting a middle- or bottom-box response were unsatisfied.

In addition to the HCAHPS survey responses, we obtained the admission and discharge dates corresponding to each survey and the survey response time. The survey response time was defined as the time elapsed between patient discharge and our institution's reception of the completed survey. Additionally, data on patient-reported overall health, mental health, and education level for each patient were obtained from their HCAHPS survey responses. Overall health and mental health are HCAHPS 
survey questions based on a Likert scale, ranging from poor to excellent.

\section{Statistical Analysis}

Data were analyzed using IBM SPSS (version 25.0, IBM Corp.). Descriptive statistics summarizing preoperative patient characteristics were compared using chisquare tests for categorical variables, Student t-tests for normally distributed continuous variables, and MannWhitney U-tests for nonparametric variables.

A baseline multivariable logistic regression model was then developed to analyze the association between patientlevel characteristics and overall satisfaction with the hospital experience. Patient characteristics with $\mathrm{p}<0.20$ were included in this baseline model, including overall health status, history of lumbar spine surgery, chronic renal failure, cancer, stroke, survey response time, length of hospital stay, and mental health status. Additionally, race was included in our statistical model as a clinically relevant covariate. Next, each of the 22 survey items were added to the baseline model individually, and we estimated a new statistical model for each survey item that adjusted the odds ratios for the clinically and statistically relevant patient-level covariates described above. This analysis allowed us to determine which components of the lumbar spine surgical inpatient experience are most strongly associated with high overall hospital satisfaction. Due to the high correlation between individual items on the HCAHPS survey, the inclusion of multiple HCAHPS items in a single model would have introduced problems of collinearity. The $\mathrm{p}$ values were adjusted using the Holm-Bonferroni method to control the family-wise error rate, thus limiting the probability of making a type I error.

\section{Results}

A total of 453 surveys from patients who underwent lumbar spine surgery were analyzed. Of these surveys, $80.1 \%$ recorded a top-box OHR, thus composing the satisfied group. The mean patient age $( \pm \mathrm{SD})$ in the satisfied group was $63.9 \pm 10.9$ years compared with $62.8 \pm 12.3$ years in the unsatisfied group $(\mathrm{p}=0.381)$. In the satisfied group $57.6 \%$ of patients were male, compared with $52.2 \%$ in the unsatisfied group $(\mathrm{p}=0.359)$. Furthermore, $93.0 \%$ of satisfied patients were white, compared with $96.7 \%$ of the unsatisfied patients $(\mathrm{p}=0.203)$. The only patient characteristic that differed significantly between patients who were satisfied and those who were unsatisfied was patient-reported overall health status $(\mathrm{p}=0.031)$. All other preoperative patient characteristics measured were similar between our 2 study groups. These results are presented in Table 2.

In our baseline multivariable logistic regression model, overall health status (OR $0.63,95 \%$ CI $0.43-0.91)$ was the only variable found to be a significant predictor of overall satisfaction with the hospital experience (Table 3). Diminishing overall health status was observed to be a negative predictor of overall satisfaction. The individual survey items that were associated with the greatest increased odds of overall satisfaction were: hospital staff always did everything they could to help with pain (OR 12.5, 95\% CI
TABLE 2. Population overview

\begin{tabular}{|c|c|c|c|}
\hline Variable & Unsatisfied & Satisfied & $\begin{array}{c}p \\
\text { Value }\end{array}$ \\
\hline No. of patients & $90(19.9)$ & $363(80.1)$ & \\
\hline Mean age in yrs & $62.8 \pm 12.3$ & $63.9 \pm 10.9$ & 0.381 \\
\hline Sex & & & 0.359 \\
\hline Male & $47 / 90(52.2)$ & $209 / 363(57.6)$ & \\
\hline Female & $43 / 90(47.8)$ & $154 / 363(42.4)$ & \\
\hline Race & & & 0.203 \\
\hline White & $87 / 90(96.7)$ & $334 / 359(93.0)$ & \\
\hline Other & $3 / 90(3.3)$ & $25 / 359(7.0)$ & \\
\hline Overall health & & & $0.031^{*}$ \\
\hline Excellent & $2 / 83(2.4)$ & $37 / 351(10.5)$ & \\
\hline Very good & $27 / 83(32.5)$ & $137 / 351(38.7)$ & \\
\hline Good & $37 / 83(44.6)$ & 142/351 (39.6) & \\
\hline Fair & $16 / 83(19.3)$ & $38 / 351(10.5)$ & \\
\hline Poor & $1 / 83(1.2)$ & 2/351 (0.6) & \\
\hline Mental health & & & 0.095 \\
\hline Excellent & 19/82 (23.2) & 131/353 (37.1) & \\
\hline Very good & $40 / 82(48.8)$ & $129 / 353(36.5)$ & \\
\hline Good & 16/82 (19.5) & $72 / 353(20.4)$ & \\
\hline Fair & $7 / 82(8.5)$ & $19 / 353(5.4)$ & \\
\hline Poor & $0 / 82(0.0)$ & $2 / 353(0.6)$ & \\
\hline Education level & & & 0.358 \\
\hline$\geq$ college & $20 / 83(23.5)$ & $87 / 352(24.9)$ & \\
\hline College & 19/83 (22.4) & $63 / 352(17.6)$ & \\
\hline Some college & $25 / 83(30.6)$ & $104 / 352(29.1)$ & \\
\hline High school & $16 / 83(20.0)$ & $90 / 352(26.1)$ & \\
\hline Some high school & $3 / 83(3.5)$ & $4 / 352(1.1)$ & \\
\hline 8th grade & $0 / 83(0.0)$ & $4 / 352(1.1)$ & \\
\hline Insurance status & & & 0.734 \\
\hline Medicare & $48 / 90(53.3)$ & $184 / 362(50.8)$ & \\
\hline Private & $34 / 90(37.8)$ & $145 / 362(40.1)$ & \\
\hline Medicaid/self-pay & $4 / 90(4.4)$ & $23 / 362(6.4)$ & \\
\hline $\begin{array}{l}\text { Workers' compen- } \\
\text { sation }\end{array}$ & $4 / 90(4.4)$ & $10 / 362(2.8)$ & \\
\hline Admission route & & & 0.709 \\
\hline Elective & $89 / 90(98.9)$ & $357 / 363$ (98.3) & \\
\hline $\begin{array}{l}\text { Emergency depart- } \\
\text { ment }\end{array}$ & $1 / 90(1.1)$ & $6 / 363(1.7)$ & \\
\hline Prior surgery & $40 / 90(44.4)$ & $126 / 368(34.7)$ & 0.086 \\
\hline Primary diagnosis & & & 0.656 \\
\hline Stenosis & $41 / 90(45.6)$ & $154 / 363(42.4)$ & \\
\hline DDD or spondylosis & $21 / 90(23.3)$ & $82 / 363(22.6)$ & \\
\hline Spondylolisthesis & $17 / 90(18.9)$ & $60 / 363(16.5)$ & \\
\hline HNP & $11 / 90(12.2)$ & $64 / 363(17.6)$ & \\
\hline Spondylolysis & $0 / 90(0.0)$ & $3 / 363(0.8)$ & \\
\hline \multicolumn{4}{|l|}{ Comorbidities } \\
\hline Cancer & $22 / 78(28.2)$ & $69 / 337(20.5)$ & 0.137 \\
\hline $\begin{array}{l}\text { Chronic renal } \\
\text { failure }\end{array}$ & $3 / 78(3.8)$ & $4 / 337(1.2)$ & 0.100 \\
\hline
\end{tabular}

CONTINUED ON PAGE 589 » 
» CONTINUED FROM PAGE 588

TABLE 2. Population overview

\begin{tabular}{|c|c|c|c|}
\hline Variable & Unsatisfied & Satisfied & $\begin{array}{c}\mathrm{p} \\
\text { Value }\end{array}$ \\
\hline \multicolumn{4}{|l|}{$\begin{array}{l}\text { Comorbidities (con- } \\
\text { tinued) }\end{array}$} \\
\hline Diabetes & $19 / 78(24.4)$ & 72/337 (21.4) & 0.565 \\
\hline $\begin{array}{l}\text { Coronary artery } \\
\text { disease }\end{array}$ & $9 / 78(11.5)$ & $44 / 337$ (13.1) & 0.717 \\
\hline Hypertension & $42 / 78(53.8)$ & $163 / 337(48.4)$ & 0.383 \\
\hline Stroke & $5 / 78(6.4)$ & 13/337 (4.1) & 0.319 \\
\hline Median BMI & $30.0(26.0-34.3)$ & $29.0(26.0-32.9)$ & 0.436 \\
\hline Median income & $\begin{array}{c}\$ 54,647 \\
(\$ 45,769-66,103)\end{array}$ & $\begin{array}{c}\$ 53,780 \\
(\$ 44,103-68,406)\end{array}$ & 0.797 \\
\hline $\begin{array}{l}\text { Median length of hos- } \\
\text { pital stay in days }\end{array}$ & $3(2-4)$ & $3(2-4)$ & 0.120 \\
\hline $\begin{array}{l}\text { Median survey } \\
\text { response time in } \\
\text { days }\end{array}$ & $26(17-37)$ & $21(16-35)$ & 0.088 \\
\hline Mean EQ-5D score & $0.551 \pm 0.215$ & $0.562 \pm 0.206$ & 0.687 \\
\hline Mean PHQ-9 score & $7.74 \pm 5.72$ & $7.15 \pm 5.76$ & 0.416 \\
\hline Mean PDQ score & $77.0 \pm 28.3$ & $73.4 \pm 28.7$ & 0.322 \\
\hline
\end{tabular}

$\mathrm{BMI}=$ body mass index; $\mathrm{DDD}=$ degenerative disc disease; $\mathrm{HNP}=$ herniated nucleus pulposus.

Values are presented as the number of patients (\%) unless stated otherwise. Mean values are presented as the mean \pm SD. Median values are presented as the median (interquartile range).

* Statistically significant $(p<0.05)$.

6.6-23.7) and nurses were always courteous and respectful (OR 11.0, 95\% CI 5.3-22.6). Additional survey items that were strongly associated with overall satisfaction included: nurses always listened carefully (OR 8.6, 95\% CI 4.7-15.7), medication side effects were always explained (OR 8.4, 95\% CI 3.5-19.9), personal and family preferences were always taken into account (OR 7.8, 95\% CI 4.1-15.2), doctors were always courteous and respectful (OR 7.1, 95\% CI 3.5-14.4), patient room and bathroom were always kept clean (OR 6.4, 95\% CI 3.5-11.6), patient had a good understanding of what he/she was responsible for in managing health when leaving the hospital (OR 5.8, 95\% CI 3.3-10.4), and pain was always well controlled (OR 5.7, 95\% CI 3.1-10.6). These results and the remaining significant predictors of overall satisfaction are presented in Table 4.

\section{Discussion}

Linking value-based incentive payments to the Patient Experience of Care domain exemplifies the emphasis that CMS places on patient satisfaction as an important component of quality of care. Not only are HCAHPS results used in determining hospital reimbursement, but also the results have been publicly reported since 2008. Making this information available to every potential patient creates incentives for hospitals to improve their quality of care and increases the transparency of the care provided. As the patient perception of care begins to play a more
TABLE 3. Baseline multivariable logistic regression model predicting a top-box OHR

\begin{tabular}{lcc}
\hline \multicolumn{1}{c}{ Variable } & OR $(95 \% \mathrm{Cl})$ & $\mathrm{p} \mathrm{Value}$ \\
\hline Overall health & $0.625(0.428-0.911)$ & $0.015^{*}$ \\
\hline Prior lumbar spine surgery & $0.589(0.344-1.008)$ & 0.054 \\
\hline History of chronic renal failure & $0.199(0.036-1.100)$ & 0.064 \\
\hline White race & $0.185(0.023-1.481)$ & 0.112 \\
\hline History of cancer & $0.685(0.370-1.268)$ & 0.229 \\
\hline Length of hospital stay & $1.047(0.918-1.193)$ & 0.494 \\
\hline Survey response time & $0.998(0.982-1.015)$ & 0.855 \\
\hline Mental health & $0.970(0.696-1.352)$ & 0.858 \\
\hline
\end{tabular}

* Statistically significant $(p<0.05)$.

influential role in valuing health care, it is important to understand which patient factors and constituent HCAHPS survey components predict high overall satisfaction, as measured by the HCAHPS survey.

With the increasing prevalence and cost of spine surgery in the United States, $4,8,25,28$ there exists a need to determine how to most effectively deliver a satisfying patient experience of care. Providing a satisfying inpatient experience may be under direct control of the hospital and its staff, and can therefore become a guaranteed positive outcome of spine surgery from the patient perspective, especially once the key drivers of satisfaction are elucidated. This is especially critical because, on the contrary, surgical outcomes are sometimes uncertain in spine surgery. ${ }^{21}$ Our study therefore analyzed HCAHPS responses from lumbar spine surgery patients to determine the most influential predictors of overall satisfaction in this population. We found that the 2 strongest predictors of overall satisfaction were the patient perception that the staff always did everything they could to help with pain, and that nurses were always respectful and courteous.

The HCAHPS component with the greatest odds of predicting overall satisfaction was whether the patient perceived the hospital staff to be doing everything they could to help with pain (OR 12.5, p < 0.001). Interestingly, staff effort to control pain was more strongly associated with patient satisfaction than whether the pain was actually controlled (OR 5.7, $\mathrm{p}<0.001)$. Similarly, in a surgical population of 4349 patients, Hanna et al. ${ }^{11}$ found that the odds of a patient being satisfied were 4.9 times greater if pain was controlled and 9.9 times greater if the staff performance was appropriate. Additionally, Iannuzzi et al. studied surgical patients and found that the perception of providers addressing pain control outranked actual pain control in terms of impact on global patient satisfaction..$^{13}$ Our results add to the growing body of evidence to suggest that a meaningful attempt at controlling a patient's pain in a surgical setting is more important to patients than actually controlling the pain.

Pain management programs that focus on patient-provider communication may succeed in helping patients better understand how hospital staff is working to minimize pain. In a national survey of 250 adults who underwent surgery, Apfelbaum et al. ${ }^{1}$ found that only two-thirds of patients were spoken to by a health care professional about 
TABLE 4. Individual HCAHPS items and their association with top-box OHR

\begin{tabular}{|c|c|c|}
\hline \multirow[b]{2}{*}{ Survey Item Response } & \multicolumn{2}{|c|}{ Top-Box Overall Rating } \\
\hline & $\begin{array}{l}\text { Adjusted OR } \\
(95 \% \mathrm{Cl})\end{array}$ & $\begin{array}{l}\text { Adjusted } \\
\text { p Value }\end{array}$ \\
\hline The hospital staff always did everything they could to help you with your pain & $12.47(6.56-23.70)$ & $<0.001^{*}$ \\
\hline Nurses always treated you with courtesy and respect & $10.97(5.34-22.56)$ & $<0.001^{*}$ \\
\hline Nurses always listened carefully to you & $8.61(4.74-15.65)$ & $<0.001^{*}$ \\
\hline $\begin{array}{l}\text { Before giving you any new medicine, hospital staff always described possible side effects in a way you could } \\
\text { understand }\end{array}$ & $8.39(3.53-19.91)$ & $<0.001^{*}$ \\
\hline Staff took your preferences and those of your family into account in deciding what your health care needs would be & $7.84(4.06-15.15)$ & $<0.001^{*}$ \\
\hline Doctors always treated you with courtesy and respect & $7.08(3.49-14.39)$ & $<0.001^{*}$ \\
\hline Your room and bathroom were always kept clean & $6.38(3.52-11.57)$ & $<0.001^{*}$ \\
\hline You had a good understanding of the things you were responsible for in managing your health & $5.84(3.27-10.43)$ & $<0.001^{*}$ \\
\hline Your pain was always well controlled & $5.72(3.10-10.56)$ & $<0.001^{*}$ \\
\hline You always got help in getting to the bathroom or using a bedpan as soon as you wanted it & $5.52(2.85-10.72)$ & $<0.001^{*}$ \\
\hline Doctors always listened carefully to you & $5.49(2.93-10.27)$ & $<0.001^{*}$ \\
\hline Doctors always explained things in a way you could understand & $5.01(2.73-9.18)$ & $<0.001^{*}$ \\
\hline The area around your room was always quiet at night & $4.25(2.33-7.75)$ & $<0.001^{*}$ \\
\hline Nurses always explained things in a way you could understand & $4.17(2.32-7.49)$ & $<0.001^{*}$ \\
\hline Before giving you any new medicine, hospital staff always told you what the medicine was for & $3.51(1.79-6.89)$ & $<0.001^{*}$ \\
\hline After you pressed the call button, you always got help as soon as you wanted it & $3.20(1.81-5.66)$ & $<0.001^{*}$ \\
\hline You clearly understood the purpose for taking each of your medications & $2.65(1.53-4.58)$ & $0.001^{*}$ \\
\hline Patient needed help from staff in using bathroom/bedpan & $0.47(0.24-0.90)$ & $0.024^{*}$ \\
\hline You got information in writing about what symptoms or health problems to look out for after you left the hospital & $2.94(1.07-8.13)$ & $0.037^{*}$ \\
\hline Hospital staff talked with you about whether you would have the help you needed when you left the hospital & $2.57(0.92-7.20)$ & 0.073 \\
\hline You needed pain medication during your hospital stay & $0.34(0.34-3.40)$ & 0.358 \\
\hline After leaving the hospital, you went directly to your own home & $1.41(0.66-3.01)$ & 0.377 \\
\hline
\end{tabular}

* Statistically significant $(p<0.05)$.

their pain. If, as the current results suggest, communication improves inpatient pain management, then it is possible that patient satisfaction can improve without fueling an increased utilization of opioid analgesic medications. Furthermore, DuPree et al..$^{9}$ demonstrated that improving patient satisfaction with pain management was possible by implementing the Six Sigma DMAIC (Define, Measure, Analyze, Improve, and Control) methodology.

A major concern of using HCAHPS to gauge the quality of hospital care is that patients may not have the knowledge to accurately judge the appropriateness of medical services being provided. This concern is especially pertinent to the Pain Management dimension of HCAHPS, where in response to widespread concerns over opioid analgesic misuse, CMS is finalizing the removal of the Pain Management dimension from the HVBP calculations beginning in fiscal year 2018. ${ }^{6}$ Despite their removal from HVBP calculations, the strong association between pain management and overall satisfaction seen in our study will persist. As such, effective pain management will continue to be reflected in CMS's reimbursement calculations, albeit indirectly. Further research is required to understand how prescribing patterns influence HCAHPS scores.

Perceiving nurses as always courteous and respectful was the second strongest predictor of top-box OHR in our population, with an odds ratio of $11.0(\mathrm{p}<0.001)$. The importance of nursing care as it relates to patient satisfaction has been observed in several prior studies. ${ }^{13,16,20} \mathrm{In}$ a retrospective study analyzing 978 HCAHPS responses in a multispecialty surgical department, Iannuzzi et al. ${ }^{13}$ found that patients who perceived their nurses as always being respectful were most likely to have experienced top-box OHR. Furthermore, in a cross-sectional study on HCAHPS responses at 430 hospitals, Kutney-Lee et al. ${ }^{20}$ found that better nurse work environments, including high nurse-to-patient ratios, were associated with better patient experience and higher HCAHPS scores. In a prospective study by Kennedy et al., ${ }^{16}$ implementing nurse manager rounding, postdischarge phone follow-up, and improved discharge teaching skills in a 28-bed surgical unit in a hospital improved patient satisfaction steadily over the 18-month duration of the study. Another study found that nurses responding to cues from patients in cancer care was independently related to their satisfaction. ${ }^{26}$ Similar quality improvement efforts might also improve patient satisfaction among lumbar spine surgery patients, given that our results suggest that nursing care is a significant component of the overall patient experience for patients undergoing lumbar spine surgery.

Doctor communication was also a statistically significant predictor for all 3 measures evaluated by HCAHPS: doctor respect, doctor listening, and doctor explanations. 
Results reported by Iannuzzi et al. ${ }^{13}$ regarding patients treated in a multispecialty surgical department further support this association between doctor communication and overall satisfaction. In a quality improvement effort, Boissy et al. conducted a study analyzing 3488 physicians in a large, multispecialty medical center to determine the effect of relationship-centered communication skills training on HCAHPS scores. ${ }^{5}$ The authors found that HCAHPS scores improved significantly following the communication skills training. Notably, improvements were similar for surgeons and nonsurgeons. Therefore, system-wide communication training programs involving spine surgeons have the potential to improve HCAHPS scores and offer a reasonable opportunity to realize a return on investment for quality improvement efforts.

While pain management and patient-provider communication were the strongest predictors of overall satisfaction, always keeping the patient's room and bathroom clean was also a strong predictor of satisfaction in our population, with an odds ratio of 6.4 ( $\mathrm{p}<0.001)$. Therefore, greater attentiveness by hospital staff to cleanliness of the bedroom and bathroom may be an effective means of improving patient satisfaction among patients undergoing lumbar spine surgery. Based on the results of the present study, attentiveness of hospital staff to these issues may lead to more satisfying care for lumbar spine surgery patients.

Although no spine care pathway was implemented at our institution during the time of our study, purported benefits of integrated care pathways include improved collaboration, professionalism, effectiveness of care, physicianpatient communication, and patient satisfaction. ${ }^{7,15,17,23}$ However, criticism has been made regarding the focus of care pathways on cost reduction over quality improvement, ${ }^{2}$ and a previous study analyzing a total knee arthroplasty population demonstrated no association between care pathways and patient satisfaction. ${ }^{12}$ Moving forward, it will be interesting to monitor how increasing standardization of care impacts the patient experience.

\section{Limitations and Strengths}

This study is limited by its observational and retrospective nature. Additionally, these data reflect patient experience measured at a single institution, thus potentially limiting the generalizability of these findings. Furthermore, since a unique multivariable logistic regression model was created for each individual survey question, relative comparison between the odds ratios is limited. Importantly, our primary outcome was only one of the 9 dimensions of the patient experience captured by the HCAHPS questionnaire that are used in calculating a hospital's TPS for the HVBP program. However, we felt that OHR was the most appropriate outcome to study because it is the only global dimension measured on HCAHPS that is used for HVBP calculations. As such, we believed that the overall rating of the hospital was the best measure of overall satisfaction with the hospital experience, especially since the other 8 dimensions focus on specific components of care (i.e., nursing communication). Finally, our patient population consisted of patients undergoing either lumbar decompression or fusion, so it is possible that procedure-specific variables led to differential experiences in the hospital experience that were not captured in this study. Despite these limitations, the present study is the first to quantify the association between each patient experience dimension and overall satisfaction among the inpatient lumbar spine surgery population.

\section{Conclusions}

Under HVBP, the patient experience of care is increasingly being used to determine hospital and physician reimbursement. The present study analyzed the key drivers of patient satisfaction with their overall hospital experience among patients undergoing lumbar spine surgery and found several important associations. Patient-reported overall health status was independently associated with top-box OHR. Regarding individual elements of the patient experience, hospital staff always doing everything they could to help with pain and nurses always being respectful were the strongest predictors of overall satisfaction in this population. These findings highlight opportunities for quality improvement in the setting of lumbar spine surgery.

\section{Acknowledgments}

We acknowledge Tyler Kinzy for his assistance with data analysis.

\section{References}

1. Apfelbaum JL, Chen C, Mehta SS, Gan TJ: Postoperative pain experience: results from a national survey suggest postoperative pain continues to be undermanaged. Anesth Analg 97:534-540, 2003

2. Atwal A, Caldwell K: Do multidisciplinary integrated care pathways improve interprofessional collaboration? Scand J Caring Sci 16:360-367, 2002

3. Badia X, Diaz-Prieto A, Gorriz MT, Herdman M, Torrado H, Farrero E, et al: Using the EuroQol-5D to measure changes in quality of life 12 months after discharge from an intensive care unit. Intensive Care Med 27:1901-1907, 2001

4. Bae HW, Rajaee SS, Kanim LE: Nationwide trends in the surgical management of lumbar spinal stenosis. Spine (Phila Pa 1976) 38:916-926, 2013

5. Boissy A, Windover AK, Bokar D, Karafa M, Neuendorf K, Frankel RM, et al: Communication skills training for physicians improves patient satisfaction. J Gen Intern Med 31:755-761, 2016

6. Centers for Medicare and Medicaid Services: Medicare Program: Hospital Outpatient Prospective Payment and Ambulatory Surgical Center Payment Systems and Quality Reporting Programs; Organ Procurement Organization Reporting and Communication; Transplant Outcome Measures and Documentation Requirements; Electronic Health Record (EHR) Incentive Programs; Payment to Nonexcepted OffCampus Provider-Based Department of a Hospital; Hospital Value-Based Purchasing (VBP) Program; Establishment of Payment Rates Under the Medicare Physician Fee Schedule for Nonexcepted Items and Services Furnished by an OffCampus Provider-Based Department of a Hospital. Fed Regist 81:79562-79892, 2016

7. Dalton P, Macintosh DJ, Pearson B: Variance analysis in clinical pathways for total hip and knee joint arthroplasty. $\mathbf{J}$ Qual Clin Pract 20:145-149, 2000

8. Deyo RA: Treatment of lumbar spinal stenosis: a balancing act. Spine J 10:625-627, 2010 
9. DuPree E, Martin L, Anderson R, Kathuria N, Reich D, Porter $\mathrm{C}$, et al: Improving patient satisfaction with pain management using Six Sigma tools. Jt Comm J Qual Patient Saf 35:343-350, 2009

10. Gatchel RJ, Mayer TG, Theodore BR: The pain disability questionnaire: relationship to one-year functional and psychosocial rehabilitation outcomes. J Occup Rehabil 16:7594, 2006

11. Hanna MN, González-Fernández M, Barrett AD, Williams KA, Pronovost P: Does patient perception of pain control affect patient satisfaction across surgical units in a tertiary teaching hospital? Am J Med Qual 27:411-416, 2012

12. Healy WL, Iorio R, Ko J, Appleby D, Lemos DW: Impact of cost reduction programs on short-term patient outcome and hospital cost of total knee arthroplasty. J Bone Joint Surg Am 84-A:348-353, 2002

13. Iannuzzi JC, Kahn SA, Zhang L, Gestring ML, Noyes K, Monson JRT: Getting satisfaction: drivers of surgical hospital consumer assessment of health care providers and systems survey scores. J Surg Res 197:155-161, 2015

14. Johnson JA, Coons SJ, Ergo A, Szava-Kovats G: Valuation of EuroQOL (EQ-5D) health states in an adult US sample. Pharmacoeconomics 13:421-433, 1998

15. Kaltenthaler E, McDonnell A, Peters J: Monitoring the care of lung cancer patients: linking audit and care pathways. J Eval Clin Pract 7:13-20, 2001

16. Kennedy B, Craig JB, Wetsel M, Reimels E, Wright J: Three nursing interventions' impact on HCAHPS scores. J Nurs Care Qual 28:327-334, 2013

17. Kitchiner D, Bundred P: Integrated care pathways increase use of guidelines. BMJ 317:147-148, 1998

18. Kroenke K, Spitzer RL: The PHQ-9: a new depression diagnostic and severity measure. Psychiatr Ann 32:509-515, 2002

19. Kroenke K, Spitzer RL, Williams JB: The PHQ-9: validity of a brief depression severity measure. J Gen Intern Med 16:606-613, 2001

20. Kutney-Lee A, McHugh MD, Sloane DM, Cimiotti JP, Flynn L, Neff DF, et al: Nursing: a key to patient satisfaction. Health Aff (Millwood) 28:w669-w677, 2009

21. Machado GC, Ferreira PH, Harris IA, Pinheiro MB, Koes BW, van Tulder M, et al: Effectiveness of surgery for lumbar spinal stenosis: a systematic review and meta-analysis. PLoS One 10:e0122800, 2015

22. Pannell WC, Savin DD, Scott TP, Wang JC, Daubs MD:
Trends in the surgical treatment of lumbar spine disease in the United States. Spine J 15:1719-1727, 2015

23. Pearson S, Moraw I, Maddern GJ: Clinical pathway management of total knee arthroplasty: a retrospective comparative study. Aust N Z J Surg 70:351-354, 2000

24. Petrullo KA, Lamar S, Nwankwo-Otti O, Alexander-Mills K, Viola D: The Patient Satisfaction Survey: What does it mean to your bottom line? J Hosp Adm 2:1-8, 2013

25. Rajaee SS, Bae HW, Kanim LEA, Delamarter RB: Spinal fusion in the United States: analysis of trends from 1998 to 2008. Spine (Phila Pa 1976) 37:67-76, 2012

26. Uitterhoeve R, Bensing J, Dilven E, Donders R, deMulder P, van Achterberg T: Nurse-patient communication in cancer care: does responding to patient's cues predict patient satisfaction with communication. Psychooncology 18:1060-1068, 2009

27. VanLare JM, Conway PH: Value-based purchasing-national programs to move from volume to value. N Engl J Med 367:292-295, 2012

28. Yoshihara H, Yoneoka D: National trends in the surgical treatment for lumbar degenerative disc disease: United States, 2000 to 2009. Spine J 15:265-271, 2015

\section{Disclosures}

Dr. Mroz: consultant for Stryker and direct stock ownership in PearlDiver. Dr. Steinmetz: royalties from Biomet, Globus, Stryker, Intellirod, and Elsevier.

\section{Author Contributions}

Conception and design: Levin, Steinmetz. Acquisition of data: Levin, Winkelman. Analysis and interpretation of data: Levin, Winkelman, Tanenbaum. Drafting the article: Levin, Winkelman, Tanenbaum, Benzel. Critically revising the article: all authors. Reviewed submitted version of manuscript: Levin, Winkelman, Tanenbaum, Mroz, Steinmetz. Approved the final version of the manuscript on behalf of all authors: Levin. Statistical analysis: Levin. Administrative/technical/material support: Benzel, Mroz, Steinmetz. Study supervision: Benzel, Mroz, Steinmetz.

\section{Correspondence}

Jay Levin: Neurological Institute, Cleveland Clinic Center for Spine Health, Cleveland, OH.jm1247@case.edu. 